\title{
Erratum to: In vitro inhibition of calcium oxalate crystallization and crystal adherence to renal tubular epithelial cells by Terminalia arjuna
}

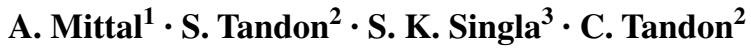

Published online: 3 May 2016

(C) Springer-Verlag Berlin Heidelberg 2016

\section{Erratum to: Urolithiasis (2016) 44:117-125}

DOI 10.1007/s00240-015-0822-0

The cited article at Ref. [36] should be corrected as follows: Thamilselvan V, Menon $\mathbf{M}$, Thamilselvan $\mathbf{S}$ (2009) Oxalate-induced activation of PKC- $\alpha$ and $-\delta$ regulates NADPH oxidase-mediated oxidative injury in renal tubular epithelial cells. Am J Physiol Renal Physiol 297:F1399-F1410.

The online version of the original article can be found under doi:10.1007/s00240-015-0822-0.

C. Tandon

tandonchanderdeep@yahoo.com

1 Department of Biotechnology and Bioinformatics, Jaypee University of Information Technology, Waknaghat, Solan, Himachal Pradesh 173234, India

2 Amity University Uttar Pradesh, Sector - 125, Noida 201313, India

3 Department of Biochemistry, Panjab University, Chandigarh 160014, India 